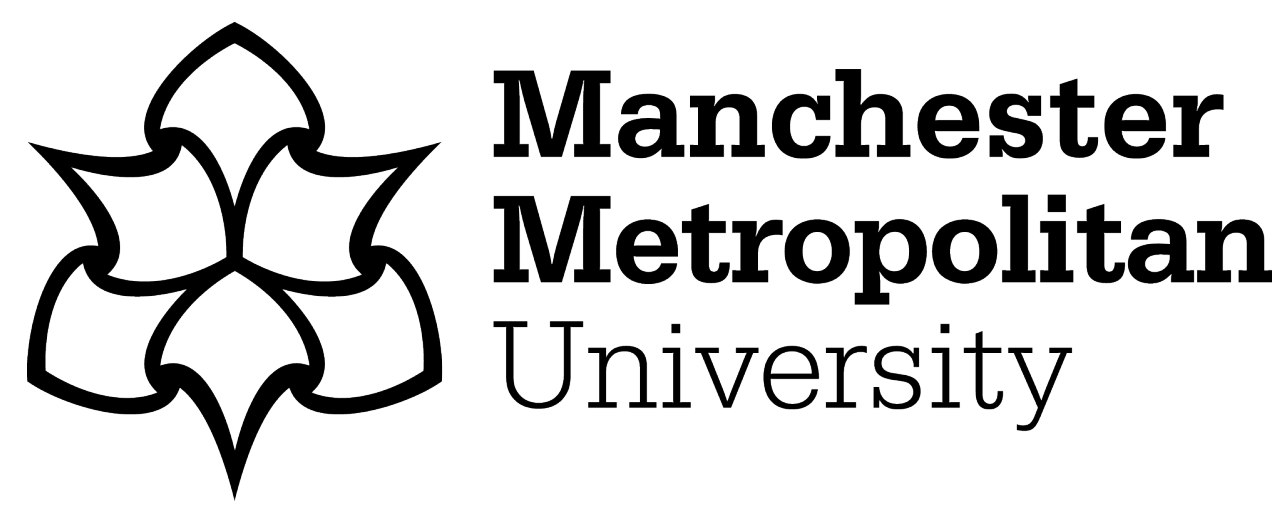

Rousell, David and Diddams, Natalie ORCID logoORCID: https://orcid.org/0000-0003-3762-3044 (2020) Fielding hilarity: sensing the affective intensities of comedy education and performance. Research in Drama Education: The Journal of Applied Theatre and Performance, 25 (3). pp. 422-440. ISSN 1356-9783

Downloaded from: https://e-space.mmu.ac.uk/626480/

Version: Accepted Version

Publisher: Informa UK Limited

DOI: https://doi.org/10.1080/13569783.2020.1766951

Please cite the published version 


\title{
Fielding Hilarity: Sensing the Affective Intensities of Comedy Education and Performance
}

\begin{abstract}
:
Laughter is a forceful expression of affective intensity. It has a potency that strikes the body directly, passing transformatively through the thinkingflesh. Laughter also carries a socially contagious intensity, capable of opening new relational spaces through the transindividual circulation of affects through a charged atmosphere. In this paper we map the circulation of affects through a series of stand-up comedy workshops with undergraduate acting students in Manchester, UK. Building on recent research on laughter and affect (Sharpe, Dewsbury, \& Hines, 2014; Willett \& Willett, 2014; Wyatt, 2019), we assemble a multi-dimensional theoretical model that enables us to follow the movement of affect across three vectors: intensity (high to low), valence (positive to negative), and temporality (past to future). By spatialising this theoretical model within the three-dimensional space of the drama studio, we show how students can use their bodies to actively perform palpable fluctuations in affectivity as they develop stand-up comedy material through a series of provocative activities. We then compose complex mappings of affective intensity as it circulates through a series of short performances, using new empirical methods to combine ethnographic accounts with data from electro-dermal activity (EDA) sensors worn by the students (de Freitas, 2018; de Freitas \& Rousell, 2018).
\end{abstract}

In moving beyond reductive accounts of laughter as a function of stimulusresponse, we assemble the concept of "fielding hilarity" to better account for the atmospheric circulation of affects through comedic learning processes and performances. We suggest that learning to perform comedy is not just about making people laugh, but about fielding a charged atmosphere through which hilarity ensues.

\section{Introduction:}


Laughter is a culmination of feeling - the crest of a wave of felt vitality. (Langer 1953, 340)

This paper builds on Suzanne Langer's process philosophy to map the circulation of affects through a series of stand-up comedy workshops with undergraduate acting students in Manchester, UK. We conceptualise the affective force of laughter as an expression of felt vitality that strikes the body directly, exhibiting a wave-like intensity that reconfigures the atmospheric relations between bodies and social milieus. Connecting Langer's biophilosophy with process-orientated approaches in affect studies (Manning 2010; Massumi 2015a; McCormack 2013), we suggest that the affective intensity of comedic events is socially contagious but largely nonconscious, capable of improvising new forms and modes of collective life through the transindividual circulation of affects within a charged atmosphere (Simondon 2009).

Our engagement with the concept of affect draws specifically on Massumi's (2002, 2015a) description of an autonomous and pre-personal force of intensity contracted from a charged field of virtual potentials. This can be understood as an atmospheric (rather than personal or emotional) reading of affect, to the extent that affect is defined as a force of felt intensity that operates environmentally; above and below the thresholds of conscious human perception and thought. As artist and philosopher Erin Manning writes:

Affect is a chorus of feelings barely felt through which events begin to take form. A body is an event for affective resonance. It becomes across affective tonalities, in a multitude of vertiginous co-becomings. (Manning 2010, 124)

This transindividual conceptualisation of affect has potentially transformative implications for pedagogical theory and practice in the performing arts, and comedy education more specifically. Our work in this area builds on a small number of recent studies that have explored the affective dimensions of laughter and comedy in a variety of contexts (Emmerson 2017; Willett and Willett 2014; Wyatt 2019). While a sustained engagement with affect theory in other areas of performance studies is now becoming more apparent (Bayly 2011; Cull Ó Maoilearca 2013; Harris and Jones 2019; Puchner 2002; Thompson 2009), affect studies of laughter and 
comedy present a relatively new field. Willett and Willett, for instance, describe laughter as a socially contagious affect that reworks the biosocial motility and porosity of bodies, 'functioning like waves rather than like properties of discrete individuals' $(2014,88)$. Recent research by Emmerson further maps the affective circulation of laughter in the context of a nursing home, drawing on non-representational geographies and Deleuze and Guattari's concept of the refrain, or 'ritornelle', to engage with 'laughter's (indeterminate) capacities to generate spaces, atmospheres and subjectivities' $(2017,2083)$. Emmerson argues that the majority of studies continue to position laughter as a representation of humour, failing to trouble the assumed linear causality of stimulus-response. Even in affective studies of humour, laughter is often conceptualised as an individualised social response (see, for instance, Sharpe, Dewsbury, and Hynes 2014; Sharpe and Hynes 2010), rather than as a transpersonal contagion that reconditions the environmental potentials for an affective atmosphere to take shape. Emmerson thus highlights the need for research that attends to ways in which 'laughter can disrupt the feel of spaces, deterritorialising and reterritorialising them towards different modes of relation between bodies, thus generating space-times that have a different atmospheric feel' (2017, 2087).

In what follows, we attempt to trace the atmospheric movement and circulation of affect in workshops and performances in which women are exploring humour and learning to perform stand-up comedy. In doing so, we aim to offer a three-fold contribution to current scholarship on the affective dimensions of laughter, comedic performance and pedagogy. First, we develop new connections between Langer's process philosophy and affective studies of laughter and comedy, assembling the concept of 'fielding hilarity' to describe the contraction of laugher from a charged field of comedic potentials. Thirdly, we construct new empirical methods for researching the circulation of affective intensities as students learn to perform stand-up comedy, combining the use of electro-dermal activity (EDA) sensors with ethnographic accounts of student engagement, improvisation, and performance.

In following these lines of inquiry into the affective dimensions of comedy education and performance, we aim to broadly contribute to what has been called the 'new empiricisms' in education and the social sciences more broadly (de Freitas 2016; St Pierre 2015). A decade ago, Clough (2009) 
diagnosed the emergence of new empiricisms in the social sciences as influenced by the process philosophies of James, Whitehead, Deleuze, Simondon and Massumi. As a key driver of the affective turn in anthropology and sociology, Clough described this new empirical movement in terms of 'an 'infra-empiricism' that allows a rethinking of bodies, matter and life through new encounters with visceral perception and preconscious affect' $(2009,44)$.

Breaking with reductive and pathologising usages of these technologies in the cognitive sciences, we instead pursue the pedagogical applications for EDA sensors to offer new empirical insights into the affective dimensions of comedy education and performance. We describe how participating theatre students were able to review video footage of their stand-up performances as synchronised with the sensor data, rendering palpable certain affective dimensions of their learning experiences that would otherwise remain invisible. This combined methodological and pedagogical approach allowed students to build deep insights into their own comedic performances and learning processes, in many cases revealing profound connections between pre-conscious affective peaks in the EDA signal and the felt intensities of the performance event. We conclude with a series of pedagogical propositions for folding the affective dimensions of laughter more intimately into the practices of comedy and drama education, drawing together Langer's bioaffective philosophy of art with the new empirical affordances of sensory technologies and media.

\section{Semblance, Expression and Felt Vitality:}

In this article, our turn to Langer's process philosophy is motivated by an interest in developing alternative theoretical and methodological approaches to comedy education and performance that pivot on the sensory, affective, and virtual dimensions of aesthetic experience (see also van der Tuin 2016). Langer's work is situated within the genealogy of process philosophy populated by thinkers such as Spinoza, James, Bergson, Whitehead, Simondon and Deleuze. Langer was Whitehead's PhD student in the early $20^{\text {th }}$ century and the first female professor of philosophy at Harvard University. Her philosophy builds on a 'minor' tradition of radical and speculative empiricism introduced by Whitehead and James, but with a specific ontological and methodological commitment to the arts as the starting point for philosophical inquiry. Langer's speculative philosophy aims to construct increasingly complex and flexible conceptual 
architectures through systematic processes of empirical experimentation, generalisation and insight rendered by encounters with visual, literary and performance art. Drawing on an extraordinary range of philosophical, anthropological and scientific sources, Langer establishes an alternative account of human (and more than human) existence, evolution and consciousness predicated on the primacy of bioaesthetic affectivity as 'felt vitality', rather than on cognition, language, or other discursive constructs ${ }^{1}$.

In her seminal works Philosophy in a New Key (1942) and Feeling and Form (1953), Langer outlines this speculative system of thought founded on the primacy of aesthetic feeling, expression and the virtual forces of what she terms 'semblances'. Langer uses the term semblance to speak of the virtual world that a work of art conjures; a form which 'reaches beyond itself' while remaining 'charged with reality' $(1953,52)$. For Langer, it is the making of the 'semblance' which enables the articulation of vital form within its scaffold. The semblance of the work is aesthetically felt without being 'seen' or otherwise consciously perceived. In other words, the semblance is felt virtually as the creation of a virtual image that emanates from - and clings to - the work of art in the form of potentials and qualities of feeling. Put simply, semblance can be understood as 'the manner in which the virtual actually appears' (Massumi 2011, 16 - original emphasis). In this sense, Langer is deeply committed to defamiliarising art and aesthetic experience from any kind of normative reduction, whether biological, psychological, social, or technical. Her concept of semblance describes how images, forms, feelings, and aesthetic experiences operate as atmospheric, virtual - even 'incorporeal' - events, generating affective realms of experience that are not (yet) perceptible, but directly felt in the body as intensity (see also Grosz 2017).

\section{An Ecology of Comedic Life:}

We begin with this discussion of Langer's larger speculative project and her concept of semblance in order to situate her theory of comedy and laughter more specifically. For Langer, comedy is a poetic dramatisation that renders

\footnotetext{
${ }^{1}$ Our turn to Langer's speculative philosophy also reflects our commitment to engage substantively with the work of a female thinker whose extensive contributions to process philosophy, the philosophy of art, and philosophy of mind have been historically overlooked. We note that several of Langer's books are currently out of print and only accessible through second-hand copies. To this end, we respond to van der Tuin's (2017) call for a contemporary re-engagement with early $20^{\text {th }}$ Century female philosophers (including Susanne K. Langer, Hélène Metzger, and Eva Louise Young) whose work is in danger of historical erasure.
} 
palpable the immediate self-enjoyment of virtual events through the rhythm of life itself. She describes comedy as the habit of entertaining a 'pure sense of life [that] is always new, infinitely complex, and infinitely variable in its possible expressions' $(1953,327)$. In Langer's analysis, the comedic is also linked to operations of eco-evolutionary accommodation, environmental reconditioning and biomorphological mutations in the animal world. The tree that deforms and gnarls its body to reach the sun; the fish that swims sideways after losing its tail; the hermit crab that makes its home in the empty head of a plastic doll washed up on the shore. For Langer, these are all examples of comedic mutations of established patterns of life and biosocial ordering which are not random or accidental mutations, but active aesthetic experimentations with new qualities of feeling and form (see also Willett 2014). Often when a living body experiments with new virtual possibilities for growth and becoming the result is comedic, precisely to the extent that it differs from normative functioning and morphology. This is to associate comedy with what Massumi (2015b) terms the 'supernormal' production of difference in the animal world, as a force of creative involution that binds art to the animal (Hansen 2000; Rousell 2019; Wyatt 2019). Such supernormal mutations always pass from life to life, body to body, semblance to semblance, individuation to individuation, milieu to milieu. They are not random adaptations of sentient life to inorganic mechanism or accident, but rather the creative fulfilment of a living movement, an expression of what Langer terms 'felt vitality'.

In her speculative analysis of comedy and laughter, Langer (1953) further describes how organisms can become more or less individuated through differentiated biosocial expressions of felt life. The more individuated an organism becomes, the greater it tends towards mortality. Langer gives the example of a jellyfish as a form of life that is potentially immortal. The jellyfish never ages, it just passes from one individuation into the next, dividing itself infinitely. The human, on the other hand, is increasingly individuated to greater degrees through its affective bonds with other beings, present or absent, dead or alive, and the construction of complex symbolic worlds. The distinctive form of life of the human is therefore defined by its felt proximity to death. The human life-feeling of inhabiting the adventure from life to death is the essence of comedy, as the very 'image of human vitality' (Langer 1953, 331). For Langer, laughter is precisely the cut that produces 'the human' as such, because laughter expresses the vital human feeling of proximity to death. Laughter, in this 
sense, is both the expression of an inhuman force of vitality that animates all things, and the particular expression of a 'felt life' that is particular to human modes of individuation, forged in the shadow of an unavoidable destiny of suffering and loss of life. Primary tools of the comic are, in this sense, the 'communal biography' of life and death, and the 'creative untruths' of artful fabulation and symbolic worlding (Grosz 2017). Both tools can be seen to express a Nietzschean affirmation of life and death, of love and loss, of failures and successes, of mutations and normalisations, of ethical paradoxes and transvaluations.

\section{Fielding Hilarity:}

Following from Langer's bioaesthetic account of the comedic force of felt life, we understand laughter as an expression of vital feeling particular to humans, but also connected to all of life through an affective atmosphere that is collectively felt (McCormack 2010, 2013; Stewart 2011). We suggest that laughter is a contraction of this super-saturated atmospheric intensity, the upsurge of a wave of feeling rather than an individualised response to an external stimulus. Drawing on the work of Manning (2010, 2013, 2016) and Massumi (2015a, 2017), we understand the atmosphere from which laughter is contracted as a virtual field of nonconscious affects, subsisting at the level of the infraindividual, or what Simondon (2009) names the 'preindividual'. Simondon describes the preindividual field as the associated milieu of a collective body-in-formation, a field of real potentials and technicities. The field could also be understood as a realm of 'pure experience' (James [1912] 2009) and 'bare activity' (Massumi 2011). The potential to laugh is always there, agitating in the atmospheric milieu of nonconscious bodily life. It is in this sense that we describe a preindividual atmosphere as charged: charged with affects, charged with potentials, charged with virtuality, charged with energy, charged with experience, charged with activity.

When laughter ensues, these infraindividual or preindividual affects come up to the level of the transindividual, as the contagious circulation of social feeling (Massumi 2017). This process is what we conceptualise as the fielding of hilarity. Here laughter achieves a particular expression of felt life. We are possessed and convulsed with laughter as a 'surge of feeling', 'the crest of a wave of felt vitality' (Langer 1953, 340). Only after the crest do we become conscious that we are laughing, as a particular relation and expression of felt experience. The field discharges and recharges, and 
perhaps more laughter ensues. These differential charges register on the surface of the skin before they become conscious. This makes EDA sensors perfect for tapping into the intensities of transindividual affects on the surface of the skin (de Freitas and Rousell 2018a), because as Massumi argues, 'the skin is faster than the word' $(2002,12)$.

In working to construct the concept of 'fielding hilarity', we are suggesting that comedy and laughter are of the order of the event. When we talk about hilarity we are not (yet) talking about an actuality, a state of affairs, or a particular aggregate and arrangement of individual bodies. Rather, we are talking about an event in Langer's sense of aesthetic feelings and semblances which come to expression within a charged field of potentials, a virtual space that is full of life, full of affectivities and socialities in the making. In this sense we never actually 'see' the comedic event, we only see semblances of what it produces (such as laughter) after the fact. Langer's concept of semblance thus helps us to understand how the virtuality of a comedic event can actually appear without being seen. 'The semblance of life is simply the mode in which virtual events are made' (Langer 1953, 245).

Our term for the particular collective expression of laughter as event is 'hilarity'. We suggest that hilarity is collectively fielded from the charged atmosphere of the affective potentials that we describe above. This makes hilarity impersonal and autonomous, because we are talking about the intensive feelings of an event rather than the emotional responses of a personal subject. With Whitehead $(1967,1978)$, we might think of hilarity in terms of the 'self-enjoyment' of the event; as a particular character of the 'subjective form' and 'affective tonality' of an event's unfolding. The laughing subject, for its part, is produced by the event of hilarity, which includes its own prior forms as a route of inheritance (we often laugh at our prior selves). 'The smile spreads over the face, as the face fits itself onto the smile' (Whitehead 1967, 71).

\section{A Methodology of Affective Atmospheres:}

The philosophical conception of fielding hilarity that we elaborate above has operated as both a theoretical and methodological touchstone for our fieldwork with a group of undergraduate acting students over a period of three months. The aim of this fieldwork was to explore the role of affective atmospheres in both conditioning and modulating the experience of 
learning to perform stand-up comedy. We wanted to create a space for experimenting with practices that explicitly folded the affective dimensions of comedy and laughter into drama-based education, combining methodological and pedagogical innovations to generate insights that were equally valuable to the students and ourselves as researchers. Methodologically, our approach draws together elements of affect studies (Manning 2010; Massumi 2002, 2015), sensory ethnography (Pink 2015; Pink \& Howes 2010), and the new empiricisms (Clough 2009; de Freitas 2016). Central to this approach is a commitment to develop new empirical methods of inquiry that attend to the invisible forces of affective intensity that circulate through social research events. While sensory ethnography has brought renewed attention to the atmospheric connections between culture, subjectivity, and sensation (Pink et al 2015), the capacity for such approaches to engage empirically with affective atmospheres has been constrained by an adherence to conventional methods of anthropological observation and description (de Freitas \& author 2018b). Affect largely eludes the observational and descriptive function of ethnography to the extent that it subsists as a prepersonal and imperceptible force that is irreducible to cognitive representation.

Our methodological innovation in this study thus hinges on an attempt to open sensory ethnography beyond the thresholds of human perception and observation, embracing the infra-empirical virtuality and affectivity of felt life. Specifically, we used electro-dermal activity (EDA) sensors to tap into the otherwise invisible circulation of affective intensities at the surface of the skin. Our methodological approach therefore moves in two directions at once. On the one hand, we are interested in rendering 'thick' ethnographic mappings of students' experiences as they learned to perform comedy for the first time, drawing on audio and video-recordings, fieldnotes, and other conventional ethnographic methods. On the other hand, we are interested in the potentials of new empirical methods to render affective data from transindividual learning events that would otherwise be imperceptible and infra-empirical. Our intention is to explore how these dual methodological movements can both support and enhance one another, to the extent that ethnographic description can be empirically augmented by affective biodata, while affective biodata can be palpably qualified through ethnographic renderings of situated contexts and atmospheric events. This approach aims to make some tentative steps toward what MacLure and author (2019) have termed a 'speculative ethnography', as an ethnography that proceeds by way of speculative 
experiments that are irreducible to methods of observation and description. In what follows, we describe these methods in more detail before sharing a speculative ethnographic vignette rendered from our comedy workshops with the students.

\section{Activating the Studio as a 3-Dimensional Model of Affect:}

The fieldwork for the project consisted of a series of comedy workshops with 7 undergraduate acting students (aged 19-22) from Manchester Metropolitan University. All participants were recruited via a notice on the theatre department's notice board, and were given detailed information outlining the research aims and the data that we would be collecting. The first workshop took participants through a series of pedagogical exercises designed to generate comedic material by drawing on affective associations, memories and intensities. We explained from the beginning that the concepts of affect and intensity were pivotal for the study as well as our pedagogical approach, and discussed these concepts with the students from a variety of perspectives.

We also worked to embody the concept of affect in the drama studio by constructing a multi-dimensional theoretical model of affect across three vectors: intensity (high to low), valence (positive to negative), and temporality (past to future). By spatialising this theoretical model within the three-dimensional space of the drama studio, we were able to explore how students could use their bodies to actively perform palpable fluctuations in affectivity as they developed stand-up comedy material through a series of provocative activities (see figure 1 ). This also helped to make the concept of affect more embodied and visceral for the students. We used string lines to extend the three vectors - or dimensions - of affect across the space of the studio. The vector of valence ran from left to right across the room; the vector of intensity ran from the ground to the ceiling; and the vector of temporality ran from the entrance door to the back of the studio. We used sheets of paper to mark the pole at the end of each vector (e.g 'low', 'high', 'past', 'future'). This configuration of the space meant that the centre of the room functioned as a kind of baseline from which different constellations of affective memory, sense, or anticipation could be embodied and discerned. 


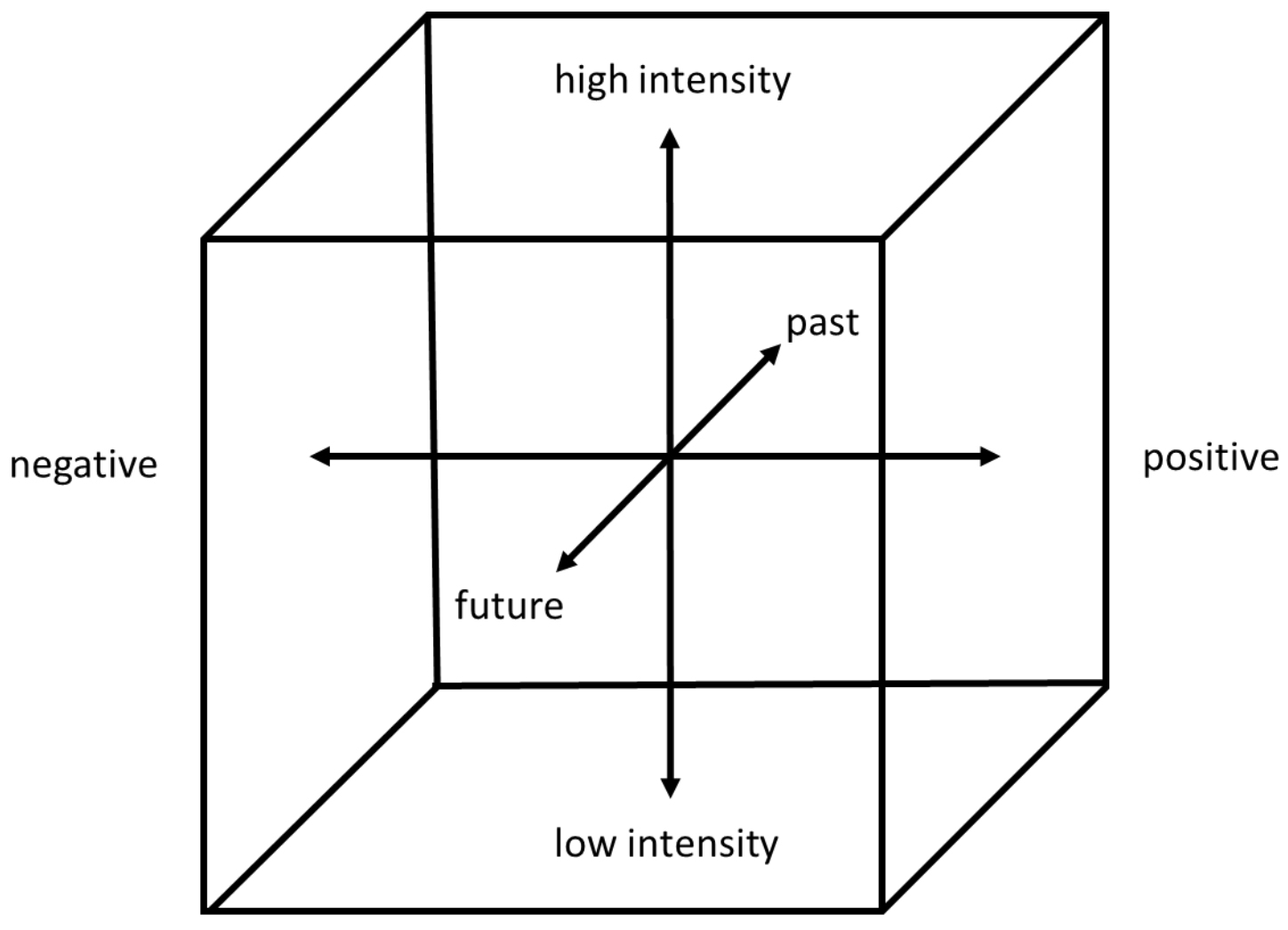

Figure 1: Tri-dimensional model of affect used to spatialise pedagogical practices for developing comedy material in the drama studio.

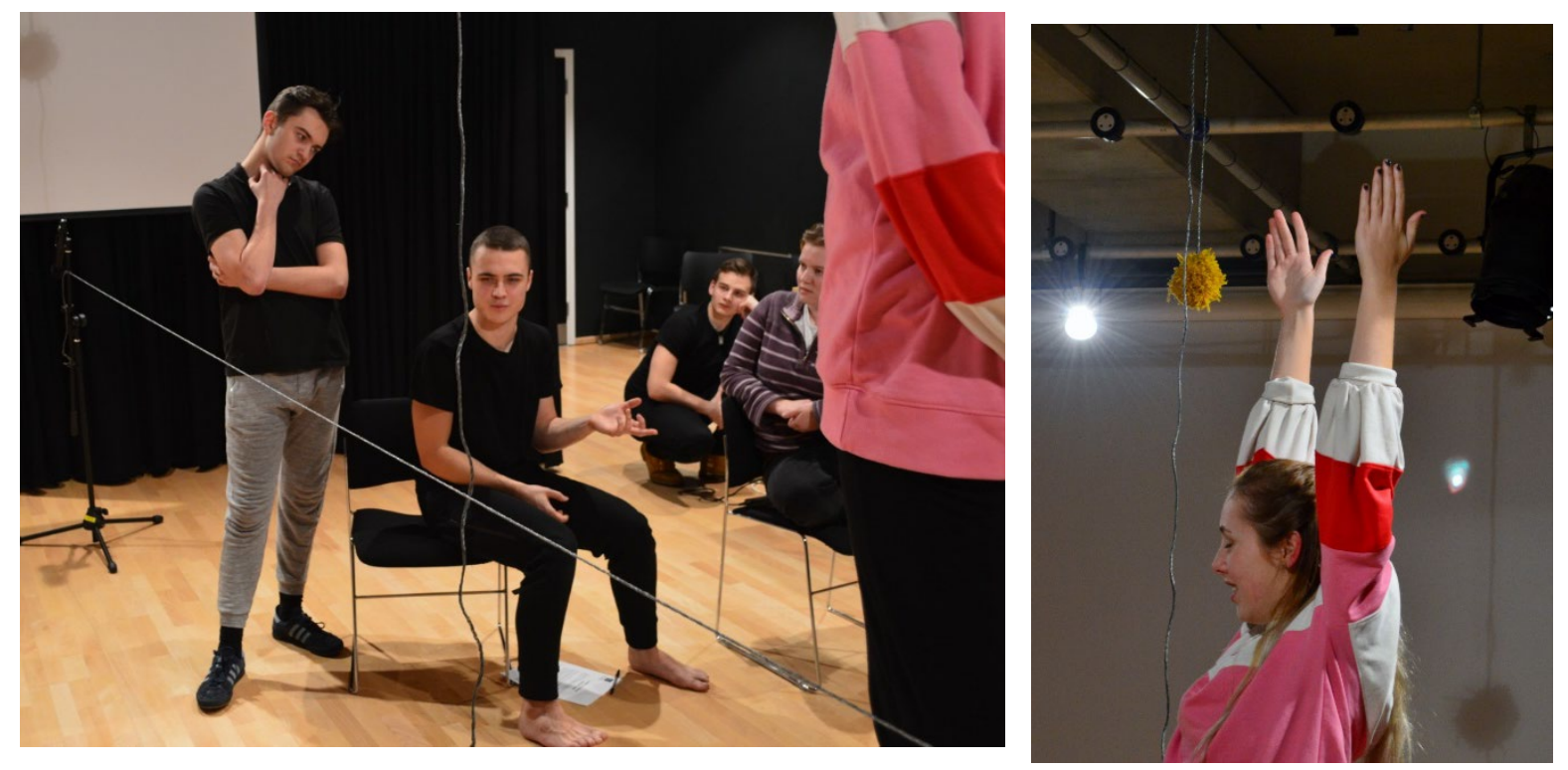

Figure 2: Students inhabiting the tri-dimensional model of affect in the drama studio.

In preparation for developing their stand-up routines, the acting students were asked to recollect stories and experiences that were funny, silly, ridiculous, or that engaged their interest in comedy. They were also 
encouraged to use their own appearances, memories and cultural backgrounds as starting points for developing stand-up material using techniques of self-deprecation, irony and sarcasm. This practice of deterritorialising the self became a central element of workshop activities, as the students were encouraged to explore elements of their own lives and experiences that could be mobilized and twisted for comedic effect.
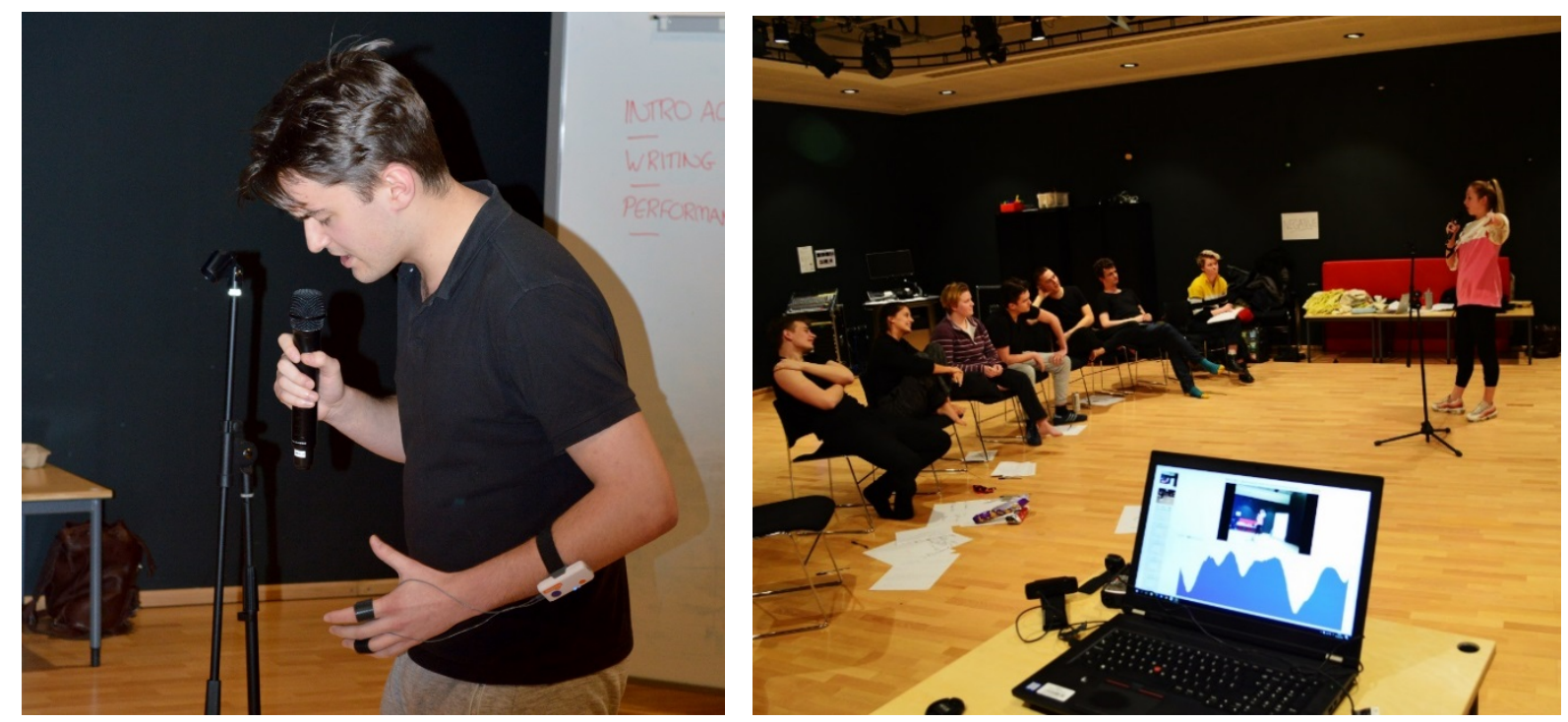

Figure 3: A student wearing the Shimmer GSR biosensor (left); and the Mobile Workstation collecting live sensor data via Bluetooth as another student performs.

\section{Mapping affective intensity using EDA sensors}

The reconfiguration of the drama studio as a live model of affectivity introduced the theatre students to an initial conceptual and physical understanding of affect as they developed their ideas for a stand-up routine. This served as a baseline from which to engage more intensively with the circulation of affect using EDA sensors. We introduced the sensors by explaining how they measure unconscious changes in electrical activity on the surface of skin, and how these changes are linked to the affective intensity of the sympathetic or 'peripheral' nervous system (de Freitas 2017; Wilson 2015).

Each of the students were then fitted with a Shimmer GSR sensor, consisting of a digital sensor strapped to the wrist and two analogue electrodes attached to their fingers. We explained that these sensors work by calculating the differential of electrical activity as it passes between two 
electrodes connected to the fingers (see figure 3, left). These electrical differentials are then measured in microsiemens and are linked to microscopic variations in the skin's electrical charge. The raw EDA signal is sampled at $128 \mathrm{Htz}$, digitally packaged, and transmitted from the wearables to a laptop via Bluetooth, where it is synchronised with video and audio (see Figure 3, right). This allowed us to generate complex affective mappings of each student's comedic performance, revealing variable peaks of intensity as the students fielded the atmospheric conditions for laughter, thought and improvisation in the drama studio.

\section{Collective Analysis of Performance and EDA Data:}

For the second workshop, we invited the theatre students to participate in a collective analysis of their performances augmented by the EDA sensor data. In between sessions we had run several analytic algorithms on the data using iMotion's biometric software to separate the EDA signal into two parts: the tonic signal and phasic signal. The tonic signal is typically associated with slow, adaptive responses to environmental changes, shown in figure 4 as variable change over time. For instance, walking into a building induces an adaptive response in the tonic signal as the body autonomously adjusts to changes in light, temperature, acoustics and ambience. The tonic signal therefore suggests an atmospheric resonance between bodily, architectural and climatological thresholds. Alternatively, the phasic signal is related to peaks of intensity in the EDA signal, which are shown in figure 4 as red arrows. The phasic peaks are like little spikes of intensity that increase in amplitude and frequency when the sympathetic nervous system becomes aroused, typically indicating anxiety, engagement or excitement. 




Figure 4: Tonic and phasic components of the EDA signal as a student performs stand-up comedy over a two-minute period.

In the second workshop, we collectively analysed the intensive dimensions of each performance from the perspectives of both audience and performer. First, we viewed each of the performances on video without the EDA data, while each student drew a line onto tracing paper which could go higher or lower in relation to the felt intensity of the performance over time (see figure 4). Secondly, we reviewed the same performance on video; but this time, the video was augmented with the tonic and phasic components of the EDA signal. We stopped the video and data stream at various points to discuss what was happening and to add annotations to the data. Our discussions during this analysis session further revealed students' ability to sense the atmospheric circulation of affects in the room during each performance, while also suggesting connections between phasic peaks, laughter and improvisation. Because the phasic peaks have a three-second latency, many of the students were counting rhythmically to establish where the actual peaks were falling as we replayed their performance with the data. This rendered a palpable sense of comic timing as what Langer calls the 'rhythm of felt life'; as the rise and fall of an aesthetic movement of feeling and thought.

\section{Ethnographic Vignettes:}

In our analysis of the data rendered through these methods, we developed a series of multi-sensory ethnographic vignettes that follow the individuated and processual experiences of the theatre students as they engaged with each element of the project. In resisting the convention of thematic coding which would attempt to reduce and distil insights from the 
data, our focus on individuals aims to follow the atmospheric movements of thought, affect and sensation through sensory ethnographic storytelling. Drawing again on Simondon, we approached these vignettes with an atmospheric interest in processes of individuation, or ontogenesis, that carry the charge of a preindividual, collective milieu:

Participation, for the individual, is the fact of being an element in a greater individuation, via the intermediary of the charge of preindividual reality that the individual contains, that is, via the potentials that the individual contains (Simondon 2009, 8).

Our ethnographic vignettes combine EDA sensor data with audio and video recordings, annotations, transcriptions and field notes to assemble 'thick' renderings of such individuations in process. This reflects an attempt to conserve the liveliness of data as an anarchival tracing of affective intensities (Massumi 2016), data that subsists as a kind of 'afterlife' of the event of individuation that can be reanimated and reexperienced.

In taking this speculative ethnographic approach, we are not interested in making causal or quantifiable claims about EDA data that refer back to an individual person. Rather, our aim is to use EDA data to help render the qualitative sense of an affective atmosphere that is environmentally dispersed within events of individuation. In other words, we are interested to use EDA data to help tell speculative ethnographic stories that reveal otherwise invisible movements and intensities of individuation. While we lack the space here to share ethnographic vignettes for all the students who participated, we have selected Jack's vignette as an example that crystallises a number of key insights from the larger project ${ }^{2}$.

\section{Jack: Grasping for Thought:}

Jack walks into the drama studio and circles the space with a lanky sense of continuous movement. Like several of the other theatre students he's wearing a black t-shirt and black jeans, but while most of the others immediately kick off their socks and shoes in preparation for the comedy workshop, Jack keeps his oversized construction boots on. These boots become a salient feature in the first exercise of the workshop, which asks

\footnotetext{
${ }^{2}$ Each of the student's selected their own pseudonym and agreed for their data to be stored, analysed, and published under this name.
} 
the students to perform some kind of ironic, satirical, self-deprecating, queer, or otherwise comedic 'twist' on their own appearance or sociocultural background. One student jokes about the benefits of her deaf ear when she goes out on dates; another performs a satirical twist on her desi heritage. When it comes to Jack's turn, he simply performs a high kick which sends his construction-booted right foot well over his head. A ripple of surprised laughter courses around the room. He does the kick again. It's a collective event, now becoming a refrain. Apparently he trains every week as a dancer. Who would know? Jack's kick performs an opening cut between a body's appearance and its affective expression of what a body can do. Jack's appearance (including the boots) bears a suggestion of masculine labour, fitness, even sportiness, but the kick bears an expression of a more feminised flexibility and litheness. This cut between the appearance and the expression of a body fields the conditions for laughter.

A bit later in the workshop, we ask the students to remember a time when they experienced an affective connection or resonance with comedy, and to situate this experience within the tri-dimensional model of affect that we'd constructed in the room. One student stands on a chair and reaches way up high to position the highest possible intensity for her memory. Most of the others stand or sit on chairs to model a relatively moderate intensity of feeling. But Jack crouches down super low in his construction boots, inhabiting a low intensity affective moment from the far corner of the past.

The memory feels more significant... as I get older, but it's like, it's quite a low intensity thing. But um, it's my first memory of... my Dad, really and it was like when we first bonded... We were watching Laurel \& Hardy, and Jeeves \& Wooster, and I'd never seen them before and he put them on, and er, we were both just laughing at it and it's the first time I remember us laughing at something together... even now, it's... it's our main bond... he finds something he thinks is funny and he sends it to me.

Here Jack makes another cut into what Langer calls the 'felt life' of comedic experience. The memory itself registers for Jack as low intensity, just hanging out with his Dad watching classical comedy routines as a young child. But this low intensity encounter with comedy accumulates sticky affective resonances and bonds as Jack grows older. Indeed, Jack describes the exchange of laughter and comedic sensibility as becoming 'the main bond' between himself and his father. This connects with Langer's 
speculative claim that comedy is fundamentally connected to the bioaesthetic expression of life's rhythms, events and felt interdependencies. Jack explains the significance of this atmospheric sense of sociality in a subsequent conversation about the workshop experience:

There was a sense that there needs to be an atmosphere that allows you to be comfortable... to be an exaggerated version of yourself, but that doesn't remove the risk of some of the things that you're saying. And I think we did that by creating a shared experience, by talking about our history with comedy and things like that... I think that so much of comedy is a shared experience... you feel like you're experiencing it for the first time with this person and all these other people.

As he prepares to do his first stand-up comedy performance, Jack is particularly interested in the wearable EDA sensor that we are fitting onto his arm. He wants to see what the EDA data is doing on the Mobile Workstation, but then he gets called to the stage to perform. He saunters up to the mic and grabs it. We're watching the EDA signal go up and down on the live stream from the sensor as Jack starts performing. Later, we used peak analysis software to mark the phasic peaks in Jack's EDA signal while he performed, which are noted in the following performance transcript.

Yo [laughter/peak].

So I, I've got a thing about sharks. Ok. This isn't really a joke this is just a fact. I'm just terrified of sharks... There's a good reason to be terrified of sharks, because... [peak] sharks haven't changed for about... [peak] a couple of million years, right, they can smell blood 8 miles away, and they don't sleep. That's fucked [laughter/peak]... I don't know if you've ever met an insomniac... [peak] but (a) they're grumpy, (b) productive AS FUCK... [laughter]. They use the full 24 hours you are allotted... [peak] you only use... [maximum] 16.. [peak] right, that is insanity... [peak] the amount that these sharks do. If sharks had legs, we'd be fucked... [peak] it would be the end of... human civilisation. We grew legs, right and we're fucking idiots [laughter/peak]. So if we can do it, AND we're fucking their oceans up, they've got problems with us! They're gonna be communicating... [peak] ... aaaaaaaaaaaa [laughter]. 
Jack tells us later that he had pretty much no idea what he was going to talk about, and that the peaks corresponded precisely with the moments when he was blanking out and 'grasping for a thought'. He'd developed some material earlier in the workshop, but all of that went out the window when he picked up the mic. Jack was improvising, and the phasic EDA peaks seem to mark the very intervals when he needed to feel his way through to the next thought. He didn't know what to talk about, so he started talking about sharks. He didn't know any jokes about sharks, so he started improvising with some basic biophysical facts. This rap about sharks quickly morphed into a speculative thought experiment: what if sharks evolved out of the ocean and grew legs, like us? We'd be doomed!

As Langer writes, comedy is an expression of the felt qualities, rhythms and intensities of biological life in the animal world:

Even the element of aggressiveness in comic action serves to develop a fundamental trait of the comic rhythm - the deep cruelty of it, as all life feeds on life. There is no biological truth that feeling does not reflect, and that good comedy, therefore, will not be prone to reveal (Langer 1953, 349).

Jellyfish are immortal, but humans know they will die. The fact that sharks can kill and eat humans is funny because it pivots on the human sense of mortality, and the capacity to laugh in the face of imminent death. Evoking the idiocy and absurdity of the human condition in relation to nonhuman life, Jack disrupts comfortable notions of anthropocentrism and human exceptionalism, while simply improvising on the fly (Willett 2014). In Langer's terms, Jack is working the invisible semblances of the comedic event by materialising the virtual relations between thoughts and things: an insomniac, a shark with legs, it never sleeps. But there's more:

Anyway that's just the shark thing, but um... [peak]... um... [peak]... one time I was really pissed with my mate and... we were playing cards and uh.. [peak]... uh... [peak] there was this fly buzzing around, and er [peak] and I was really drunk, and I thought 'fuck it I'll grab it' [peak]. And I grabbed it out of the air by the wing, like, like a fucking ninja [laughter/peak]. Right, so I was... thrilled at first, I was like 'fuck yeah!'. I was really proud of this story. And then... [peak] I kinda got a little bit scared, because 
I thought... [peak]... 'What if I'm Jason Bourne?' [laughter/peak]. Because he doesn't know, I don't know man, y'know. What if... the reality of it is... [peak]... I'm Jason Bourne? But... with none of the looks [peak]... y'know the shaved body [peak]... or the money [laughter/peak] that he definitely had access to. I've recently got a new cyborg [peak]... sort of implant thing [peak]... [waves the EDA sensor around] that I might be able to use, but apart from that... I've not got anything really... that Jason Bourne has... [peak]... so.

But in other news, [peak] if sharks do come aboard, right, come to me [laughter/peak]. Jason Bourne, we might sort it out for you... [peak]. Keep your eyes on the seas, guys, keep your eyes on the seas! [cheering and applause/peaks].

How then is hilarity being fielded in this passage? Like the kick mentioned earlier, Jack makes another series of cuts into his own process as he turns the table on the predatory human-animal relationship improvised in the previous passage. Now he summons the virtual image of a fly as prey for a drunken feat of supernormal reflexes. In thinking with Langer's concept of semblance, the actual grasping of the fly and the grasping of the virtual idea of the fly merge into a single gesture. The idea of grasping the fly is born from an interval or suspension of thought in which Jack does not know what to say, an interval again marked by a phasic peak in the EDA signal. The gesture is contracted from a charged field of potential: what a body can (virtually) do.

Starting

improving

about

sharks
If sharks had

legs, we'd

be fucked
Starts telling the story of

catching the fly 


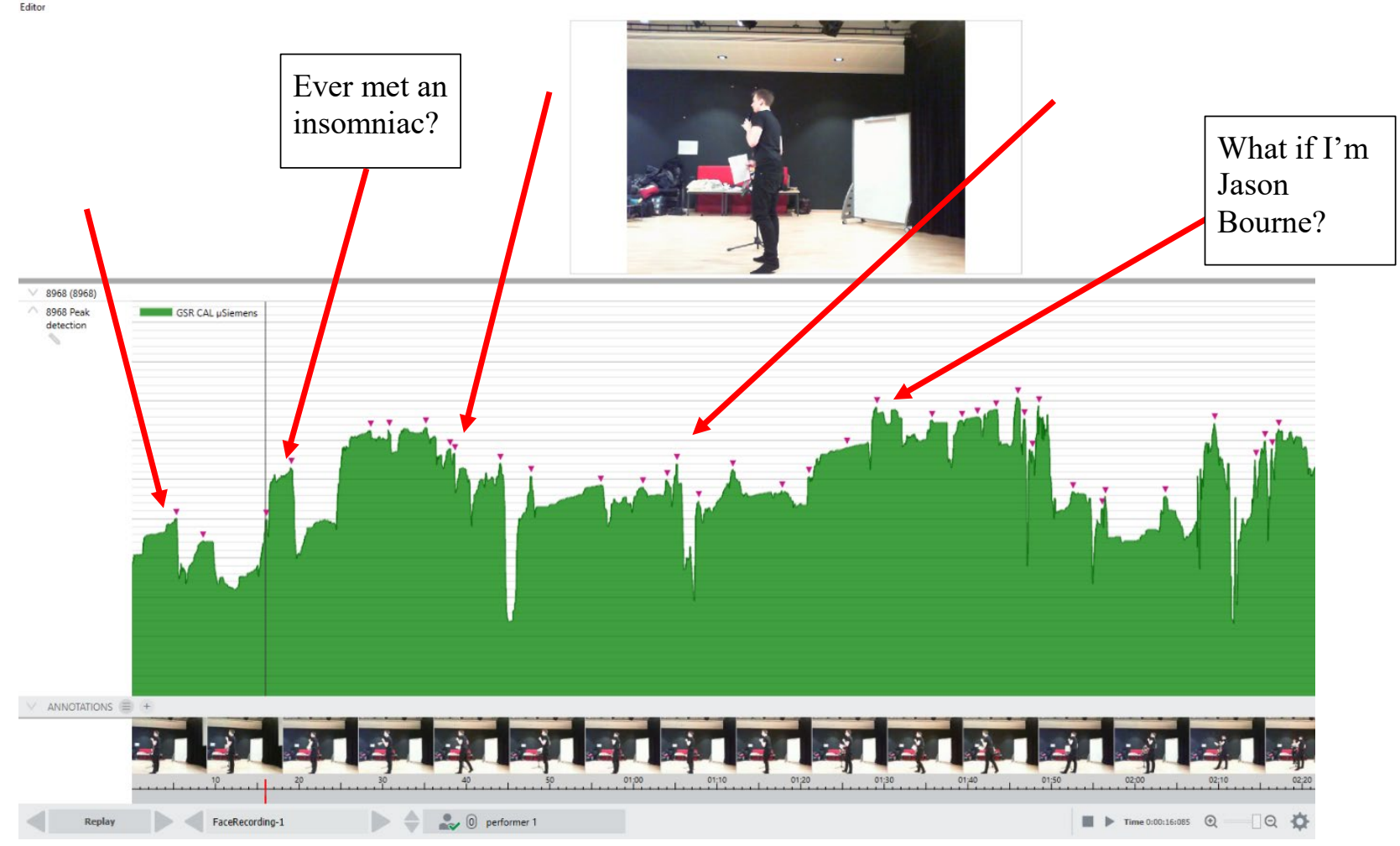

Figure 5: A screenshot showing Jack's 2:40 minute comedy performance with phasic EDA signal, phasic peaks, and textual annotation of movements in the routine.

Another series of EDA peaks appear in the signal as Jack describes the transition from elation ("fuck yeah!") to a kind of gnawing, existential fear in his improvised account of the fly-catching event. How did I just do something that I had no idea I could do? Maybe I'm not who I think I am. What if I'm Jason Bourne? A fictional character from a series of popular spy books and films, Jason Bourne is the subject of a highly classified military program that gives him 'supernormal' physical and mental abilities through extreme training and experimental drug treatments. But Bourne suffers from complete amnesia. He has no idea that he is Jason Bourne, and thus his supernormal abilities reside as latent potentials in the affective memory of the body. That is, they remain latent until these capacities are activated by events that call for them to be actuated. Then Bourne is able to do extraordinary feats, but he has no idea how he knows how to do them. Interestingly, it is the very dissolution of Bourne's identity that shifts his status from an 'asset' to a 'rogue operative' in the eyes of the military regime. Bourne is targeted for assassination precisely because he's forgotten who he is, hence his process of individuation is uncontrollable. Jack's improvised evocation of Jason Bourne conjures a virtual semblance 
of a self that is atmospheric, existing as a charged milieu of bodily potentials for individuation, rather than as a cohesive or static identity.

Thinking again with Langer, we can read Jack's improvised stream of liminal connections between sharks, insomnia, a fly, and Jason Bourne as a comedic expression of the rhythm of felt life. Hilarity is being contracted not through conscious intention and planning, but through the bodily rhythm of an articulate, but non-discursive suspension of thought. In figure 5 , we can clearly see Jack's intervals of suspended thought punctuated almost consistently with the EDA peaks. This was also narrated in Jack's responses during the data analysis session, as he watched his own video routine aligned with the EDA signal:

I can hear myself improv-ing... I have a thought, I have a thought, I have a thought, and then I have to deviate from that thought and that's always a peak as well... like: "I don't know if you've ever met an insomniac, BUT" [clicks] and that's a peak because it's like me grasping like a jump of adrenaline to get a... thought to keep the thing rolling.

We suggest that it is precisely within these intervals of not knowing - of forgetting yourself - of thinking-feeling your way through, that the phenomenon of 'fielding hilarity' occurs. Not in the intended punchline or the laugh as response, but in the interstitial gaps between affective sensation and conscious thought (Massumi 2002; Manning 2013). You have no idea what you're doing... and then suddenly you have a thought. And it's funny! The hilarity that ensues is contracted from the circulation of preconscious affective intervals from which the novelty of thought arises. Thoughts become funny when they are novel, and novel thoughts arise in the intervals when thought is suspended and deviated by the play of affectivity. Perhaps Jack's flow of individuation needed to dip back into the pre-individual field in order to 'recharge' itself with novel potentials for hilarity. As Jack describes it, a 'deviation' was needed to 'keep the thing rolling'.

\section{Conclusion:}

This paper has developed new conceptualisations and empirical insights into the affective dimensions of comedy education and performance. Connecting Suzanne Langer's biophilosophy with resonant perspectives in 
process philosophy (Simondon 2009; Whitehead 1967) affect studies (Manning 2010; Massumi 2002), and the new empiricisms (Clough 2009; de Freitas 2017), we have assembled the concept of 'fielding hilarity' in order to attend to the circulation of affective intensities within comedic events, pedagogies, and performances. We have worked to extend and problematise this affective conceptualisation of comedy through speculative ethnographic experiments with theatre students in a series of comedy workshops. This has involved the development of novel empirical methods for undertaking speculative ethnographic fieldwork, including the 3-dimensional modelling of affective states in the space of the drama studio, and the use of EDA biosensors to map variations and peaks of affective intensity as students perform comedy routines for the very first time.

The initial results of our study have yielded a number of insights that support the timeliness and relevance of affective approaches in comedy education research and practice. Specifically, we found an association between rhythmic peaks in the EDA signal as participants performed comedic routines, and their self-reported experiences of suspensions and deviations of thought that necessitated techniques of improvisation, as exemplified by our close analysis of Jack's performance and associated data. The association between EDA peaks and affective experiences of 'not knowing' and 'grasping for thought' contradict much of the existing scientific research on EDA, which typically attributes peaks to an internal response to an identifiable external stimulus. Our speculative ethnographic analysis of Jack's performance data instead supports a more atmospheric reading of affective intensity, as a process of fielding and recharging an improvised flow of individuation from a virtual reservoir of collective potentials. Drawing on Langer's concepts of 'semblance' and 'felt life' together with Simondon's theory of individuation, we suggest that these suspensions and deviations of thought are co-existing with the novelty of affective feeling, as the very force of creative advancement and improvisation of new forms and modalities of social life. Every moment is, in this sense, an opportunity to feel the world differently.

Despite the promising trajectories of this inquiry, we feel the need to maintain caution in attributing causality to particular associations between affective states and EDA data. Indeed, one of the benefits of 'staying with' ethnography as a methodological trope, however speculatively, is that ethnography has historically resisted the reductive attribution of cause and 
effect, seeking instead to thickly evoke the entangled relations between people, cultures, places and times. Our interest, however, is to move beyond ethnographic description to a more speculative and pragmatic mode of inquiry that is pedagogically oriented. Rather than using EDA data to make causal claims or to enhance ethnographic description, we are interested in what this data can do pedagogically in the drama studio. What would a performing arts pedagogy look like that placed affect at the centre of its approach? How might sensory technologies - such as EDA sensors be used to enhance the insights and sensibilities of theatre students regarding their own learning processes and performances? What "generative intervals of potential" (McCormack 2013, xii) might emerge if we took drama education as a process of collective individuation, as the improvised fielding of atmospheric qualities and potentials of social life? The theoretical, methodological, and empirical insights shared in this paper support the development of new research and pedagogical trajectories for drama education along these speculative lines of inquiry.

\section{Word Count: 8692}

\section{References:}

Bayly, Simon. 2011. A Pathognomy of Performance. Palgrave Macmillan.

Bell, Vikki. 2017. "An Interview with Elizabeth Grosz: 'The Incorporeal'." Theory, Culture \& Society 34 (7-8): 237-243 doi: 10.1177/0263276417736814.

Clough, Patricia Ticineto. 2009. "The New Empiricism: Affect and Sociological Method." European Journal of Social Theory 12 (1): 43-61 doi: 10.1177/1368431008099643.

Cull Ó Maoilearca, Laura. 2013. Theatres of Immanence: Deleuze and the Ethics of Performance. Palgrave Macmillan.

de Freitas, E. 2016. “The New Empiricism of the Fractal Fold: Rethinking Monadology in Digital Times." Cultural Studies - Critical Methodologies 16 (2): 224-234. doi: 10.1177/1532708616634733.

de Freitas, E. 2017. "The Biosocial Subject: Sensor Technologies and Worldly Sensibility." Discourse: Studies in the Cultural Politics of Education 39 (2): 292-308. ISSN 0159-6306.

de Freitas, E. and author. 2018a. "Atmospheric Intensities: Sensing the Places and Times of Learning Through Bioaffective Technologies". Paper presented at the Affects, Interfaces Events Conference, Aarhus University, 29-30 August 2018.

de Freitas, E. and author. 2018b. "Sensor Technologies and the Future of Ethnographic Fieldwork". Paper presented at the European Association of Social Anthropologists Annual Conference. Stockholm University, 14-18 August 2018. 
de Freitas, E. and author. Forthcoming. "Atmospheric Intensities: Skin Conductance and the Collective Sensing Body". In Affects, Interfaces, Events. Fritsch, J., B. Thomsen and J. Kofoed [eds]. Aarhus University Press.

Deleuze, Gilles. 1997. "Immanence: A Life..." Theory, Culture \& Society 14 (2): 3-7. doi: 10.1177/026327697014002002.

Ellsworth, Elizabeth Ann. 2005. Places of Learning: Media, Architecture, Pedagogy. Routledge. Emmerson, Phil. 2017. "Thinking Laughter Beyond Humour: Atmospheric Refrains and Ethical Indeterminacies in Spaces of Care." Environment and Planning 49 (9): 2082-2098 doi: 10.1177/0308518X17717724.

Grosz, Elizabeth. 2017. The Incorporeal: Ontology, Ethics, and the Limits of Materialism. Columbia University Press.

Harris, Anne M. and Stacy Holman Jones. 2019. The Queer Life of Things: Performance, Affect, and the More-Than-Human. Rowman and Littlefield.

Hickey-Moody, Anna. 2013. Youth, Arts, and Education: Reassembling Subjectivity Through Affect. Routledge.

James, William. 2009. Essays in Radical Empiricism (1912). Cornell University Library.

Langer, Suzanne K. 1942. Philosophy in a New Key. Harvard University Press.

Langer, Susanne K. 1953. Feeling and Form: A Theory of Art Developed from 'Philosophy in a New Key'. London: Routledge \& Kegan Paul.

MacLure, M. and author. 2019. "Participation without Observation: Toward a Speculative Ethnography." Paper presented at American Educational Research Association (AERA) Annual Conference, Toronto, Canada. 5-9 April 2019.

McCormack, Derek P. 2010. "Fieldworking with Atmospheric Bodies." Performance Research 15 (4): 40-48. doi: 10.1080/13528165.2010.539878.

McCormack, Derek P. 2013. Refrains for Moving Bodies: Experience and Experiment in Affective Spaces. Duke University Press.

Manning, Erin. 2010. "Always More than One: The Collectivity of a Life." Body \& Society 16 (1): 117-127. doi: 10.1177/1357034X09354128.

Manning, Erin. 2012. Relationscapes. The MIT Press.

Manning, Erin. 2013. Always More Than One: Individuation's Dance. Duke University Press.

Manning, Erin. 2016. The Minor Gesture. Duke University Press.

Massumi, Brian. 2002. Parables for the Virtual: Movement, Affect, Sensation. Duke University Press.

Massumi, Brian. 2011. Semblance and Event: Activist Philosophy and the Occurrent Arts. MIT Press.

Massumi, Brian. 2015a. The Politics of Affect. Polity Press.

Massumi, Brian. 2015b. "The Supernormal Animal." Chapter 1 in The Nonhuman Turn. Grusin, Richard [ed]. University Of Minnesota Press. 
Massumi, Brian. 2016. "Materializations of the Anarchive: Anarchival Propositions." Chapter 6 in The Go-To How To Book of Anarchiving. Andrew Murphie [ed]. Senselab, Concordia University.

Massumi, Brian. 2017. The Principle of Unrest: Activist Philosophy in the Expanded Field. Open Humanities Press.

Pink, Sarah. 2015. Doing Sensory Ethnography. Los Angeles: SAGE.

Pink, Sarah and David Howes. 2010. "The Future of Sensory Anthropology/The Anthropology of the Senses". Social Anthropology 18 (3): 331-333 ISSN: 0964-0282.

Pink, Sarah, Kerstin Leder Mackley and Roksana Moroşanu. 2015. "Researching in Atmospheres: Video and the 'Feel' of the Mundane". Visual Communication 14 (3): 351-369 doi: $10.1177 / 1470357215579580$.

Puchner, Martin. 2002. Stage Fright: Modernism, Anti-Theatricality and Drama. Johns Hopkins University Press.

Rousell, David. 2019. "Inhuman Forms of Life: On Art as a Problem for Post-Qualitative Research." International Journal of Qualitative Studies in Education 32 (7): 887-908 doi: 10.1080/09518398.2019.1609123.

Sharpe, Scott and Maria Hynes. 2010. "Yea-Saying Laughter." Parallax 16 (3): 44-54 doi: 10.1080/13534645.2010.486666.

Sharpe, Scott, J. D. Dewsbury and Maria Hynes. 2014. "The Minute Interventions of Stewart Lee." Performance Research 19 (2): 116-125

doi: $10.1080 / 13528165.2014 .928527$.

Simondon, Gilbert. 2009. "The Position of the Problem of Ontogenesis." Parrhesia 7 (1): 4-16. Stewart, Kathleen. 2011. "Atmospheric Attunements." Environment and Planning D: Society and Space 29 (3): 445-453. doi: 10.1068/d9109.

St Pierre, Elizabeth A. 2015. "The Empirical and the New Empiricisms." Cultural Studies Critical Methodologies 16 (2): 111-124 doi: 10.1177/1532708616636147.

Thompson, J. 2009. Performance Affects: Applied Theatre and the End of Effect. Palgrave Macmillan.

van der Tuin, Iris. 2016. "Bergson before Bergsonism: Traversing "Bergson's Failing" in Susanne K. Langer's Philosophy of Art." Journal of French and Francophone Philosophy 24 (2): 176-202 doi: 10.5195/JFFP.2016.776.

van der Tuin, Iris. 2017. "Epistemology in a Speculative Key." Keynote address at Summer Institute in Qualitative Inquiry, Manchester Metropolitan University. 10-14 July 2017.

Whitehead, Alfred North. 1967. Modes of Thought. The Free Press.

Whitehead, Alfred North. 1978. Process and Reality. Macmillan USA.

Willett, Cynthia. 2014. Interspecies Ethics. Columbia University Press.

Willett, Cynthia and Julie Willett. 2014. "Going to Bed White and Waking Up Arab: On Xenophobia, Affect Theories of Laughter, and the Social Contagion of the Comic Stage." Critical Philosophy of Race 2 (1): 84-105. ISSN 2165-8692. 
Wilson, Elizabeth. 2015. Gut Feminism. Durham, NC: Duke University Press.

Wyatt, Jonathan. 2019. Therapy, Stand-Up, and the Gesture of Writing. Routledge. 